\title{
Evaluation of Helicobacter pylori IgG levels in type 2 diabetes mellitus patients
}

\section{ABSTRACT}

Background. Diabetes mellitus (DM) is a common and debilitating chronic disease with increasing prevalence in the world and in Iran. Helicobacter pylori (H. pylori) is a gram-negative bacillus that causes gastritis and peptic ulcer disease and stomach cancer. It is more common in developing countries. Several studies have shown the possible association between $\boldsymbol{H}$. pylori infection and DM. We performed this study to evaluate $\boldsymbol{H}$. pylori infection in type 2 diabetes mellitus (T2DM) patients in comparison to non-diabetic individuals. Methods. In a case-control study 99 T2DM patients (aged 31 to 96 years) who referred to Urmia Imam Khomaini hospital and 96 non-diabetic controls were included. Venous blood samples were received from all participants and fasting blood glucose (FBG), $\mathrm{HbA}_{1 \mathrm{c}}$ and serum $\boldsymbol{H}$. pylori lgG levels were measured. For all individuals demographic data, including age, sex and body mass index (BMI) were recorded. $\boldsymbol{H}$. pylori IgG levels greater than $10 \mathrm{U} / \mathrm{ml}$ was considered as $H$. pylori infection. $\boldsymbol{H}$. pylori IgG serum levels of all of T2DM patients and control group were compared with each other. Data were analyzed using SPSS version 17. We used independent T-test, Chi-square and Fisher exact test for statistical analysis. The level of significance was considered as $\mathrm{p}$-value $<0.05$.

Results. Means age of T2DM patients and control group were $59.77 \pm 13.25$ and $63.43 \pm 13.16$ years

Address for correspondence:

Dr Neda Valizadeh

$4^{\text {th }}$ floor, Ershad Street, Imam Khomeini Hospital, Urmia, Iran

Zip Code: 81351-57157

Phone: +984433459538

Clinical Diabetology 2020, 9, 3, 179-183

DOI: $10.5603 /$ DK.2020.0012

Received: 16.02 .2020

Accepted: 09.03.2020 respectively and there was not significant difference between two groups $(p=0.05)$. Frequency of positive $H$. pylori serology in T2DM patients was $69.7 \%$ and in non-diabetic group was $66.7 \%$ and there was not significant difference between two groups in this regard $(p=0.65)$. Mean \pm SE serum $H$. pylori IgG levels in T2DM and non-diabetic subjects was $45.78 \pm 4.82$ and $44.35 \pm 4.83 \mathrm{U} / \mathrm{ml}$ respectively $(p=0.83)$. Mean $\mathrm{HbA}_{1 \mathrm{c}}$ level was significantly higher in T2DM patients compared to control group $(8.40 \pm 2.02$ and $5.29 \pm$ 0.45 respectively, $\mathrm{p}<0.001$ ).

Conclusions. According to the results of this study frequency of $\boldsymbol{H}$. pylori infection and also serum $\boldsymbol{H}$. pylori IgG levels in diabetic patients does not differ from nondiabetics subjects. (Clin Diabetol 2020; 9; 3: 179-183)

Key words: diabetes mellitus type 2, Helicobacter pylori, Helicobacter pylori serology, IgG

\section{Introduction}

Diabetes is a common and debilitating chronic disease with increasing prevalence both in the world and in Iran [1-3]. Helicobacter pylori (H. pylori) is a gram-negative bacillus that causes gastritis and peptic ulcer disease and stomach cancer [4]. It is more common in developing countries [5]. Some studies have shown that $H$. pylori infection has been associated with non-gastrointestinal diseases such as ischemic heart disease, neurologic diseases, and autoimmune thyroid disorders [5-10]. Several studies have shown the association between $H$. pylori infection and diabetes mellitus $[5,11,12]$. The issue of whether $H$. pylori infection causes diabetes or those with diabetes are more likely to develop $H$. pylori infection is still not fully understood [12]. One of the proposed mechanisms of developing diabetes in patients with $H$. pylori infection can be increased insulin resistance [5]. Other 
Table 1. Demographic characteristics and laboratory test results of type 2 diabetes mellitus (T2DM) patients and control group

\begin{tabular}{lccc}
\hline Parameter & T2DM patients $(\mathbf{n}=\mathbf{9 9})$ & Control group $(\mathbf{n}=\mathbf{9 6})$ & $\mathbf{p}$ value \\
\hline Age (years) & $59.77 \pm 13.25$ & $63.43 \pm 13.16$ & 0.05 \\
Female $(\%)$ & $53(53.5 \%)$ & $49(51 \%)$ & 0.72 \\
Weight $[\mathrm{kg}]$ & $73.56 \pm 14.44$ & $66.54 \pm 14.34$ & 0.001 \\
Height $[\mathrm{cm}]$ & $163.99 \pm 9.81$ & $161.02 \pm 10.46$ & 0.04 \\
$\mathrm{BMI}\left[\mathrm{kg} / \mathrm{m}^{2}\right]$ & $27.45 \pm 5.28$ & $25.61 \pm 4.47$ & 0.009 \\
$\mathrm{HbA}_{1 \mathrm{c}}(\%)$ & $8.40 \pm 2.02$ & $5.29 \pm 0.45$ & $<0.001$ \\
FBG $[\mathrm{mg} / \mathrm{dL}]$ & $201.69 \pm 78.71$ & $90.39 \pm 24.25$ & 0.001 \\
\hline
\end{tabular}

Data are expressed as mean \pm SD. FBG — fasting blood glucose; BMI — body mass index

mechanisms include chronic inflammation, reduced insulin secretion, and increased synthesis of some of the diabetogenic hormones such as leptin that leads to insulin resistance [5]. Furthermore decreased ghrelin level in patients with $H$. pylori infection leads to reduced energy consumption and weight gain [5].

In some studies, there is even a significant correlation between microvascular complications of diabetes and helicobacter infection such as microalbuminuria and neuropathy $[13,14]$. In contrast, in some studies, there was no association between $H$. pylori infection and diabetes mellitus found [15].

Given the controversy and limited studies in this field in Iran, we designed this study to investigate the association of $H$. pylori infection with type 2 diabetes.

\section{Materials and methods}

In this case-control study 99 type 2 diabetes mellitus (T2DM) patients over the age of thirty (aged 31-96 years) who referred to Endocrinology department of Urmia Imam Khomaini hospital and 96 non-diabetic controls were included. Subjects who had autoimmune, infectious or rheumatologic diseases and those taking proton pomp inhibitors within one month before the study as well as patients treated with immunosuppressive drugs were excluded from study.

The subjects in our study had no predominant symptoms of upper gastrointestinal tract involvement and they had not been treated with anti-helicobacter drugs for a month before study initiation. The control group was selected from non-diabetic healthy individuals who referred to the ophthalmology department of Imam Khomaini hospital and did not present any exclusion criteria.

The study began after approval of Urmia University of medical sciences ethic committee and after obtaining written consent from all individuals. Venous blood samples were received from participants in the fasting state for fasting blood glucose (FBG), $\mathrm{HbA}_{1 \mathrm{c}}$ and serum
H. pylori lgG levels. FBG and $\mathrm{HbA}_{1 \mathrm{c}}$ were measured by enzymatic method (Pars Azmun kite, Tehran, Iran) and turbidimetric immunoassay (Aptec kite, Belgium) respectively and serum $H$. pylori lgG level was measured by ELISA method (Pishtazteb kite, Tehran, Iran). For all subjects demographic data, including age, sex weight, height and body mass index (BMI) were recorded. $H$. pylori lgG levels greater than $10 \mathrm{U} / \mathrm{ml}$ was considered as $H$. pylori infection. $H$. pylori lgG serum levels of all of T2DM patients and control group were compared with each other. Data were analyzed by independent T-test, Chi-square and Fisher exact tests using SPSS version 17. The level of significance was considered as p-value $<0.05$.

\section{Results}

Demographic characteristics and laboratory test results of two study groups are demonstrated in Table 1.

As shown in Table 1, there is no statistically significant difference between the two groups in terms of age $(p=0.05)$. Also, the percentage of female population in the two groups was not statistically significant.

Both FBG and $\mathrm{HbA}_{1 \mathrm{c}}$ mean values were significantly higher in T2DM patients than in control group (Table 1). Frequency of positive $H$. pylori serology in T2DM patients was $69.7 \%(n=69)$ and in non-diabetic group was $66.7 \%(n=64)$ and there was not significant difference between these two groups in this regard ( $p=0.65)$. Mean \pm SE (standard error) serum $H$. pylori IgG levels in T2DM and non-diabetic subjects were $45.78 \pm 4.82$ and $44.35 \pm 4.83 \mathrm{U} / \mathrm{ml}$ respectively and the difference between these two groups was not statistically significant $(p=0.83)$.

FBG, $\mathrm{HbA}_{1 \mathrm{c}}$ and $\mathrm{BMI}$ mean values did not differ significantly between diabetic patients with and without H. pylori infection (Table 2). Also as shown in Table 3 the difference between $\mathrm{FBG}, \mathrm{HbA}_{1 \mathrm{c}}$ and $\mathrm{BMI}$ mean values was not statistically significant between control subjects with $H$. pylori infection and without it. 
Table 2. Glycemic parameters and BMI in diabetic patients with and without $H$. pylori infection

\begin{tabular}{lccc}
\hline & DM $\boldsymbol{H}$. pylori+ & DM $\boldsymbol{H}$. pylori- & p-value \\
\hline FBG $[\mathrm{mg} / \mathrm{dL}]$ & $191.66 \pm 64.33$ & $224.7 \pm 102.18$ & 0.05 \\
$\mathrm{HbA}_{1 \mathrm{c}}(\%)$ & $8.33 \pm 1.95$ & $8.55 \pm 2.22$ & 0.63 \\
$\mathrm{BMI}\left[\mathrm{kg} / \mathrm{m}^{2}\right]$ & $27.47 \pm 5.22$ & $27.40 \pm 5.49$ & 0.96 \\
\hline
\end{tabular}

$\mathrm{DM}$ - diabetes mellitus; FBG — fasting blood glucose; BMI — body mass index

Table 3. Glycemic parameters and BMI in control group with and without H. pylori infection

\begin{tabular}{lccc}
\hline & Control $\boldsymbol{H}$. pylori+ & Control $\boldsymbol{H}$. pylori- & p-value \\
\hline FBG $[\mathrm{mg} / \mathrm{dL}]$ & $92.73 \pm 27.86$ & $85.71 \pm 13.8$ & 0.1 \\
$\mathrm{HbA}_{1 \mathrm{c}}(\%)$ & $5.34 \pm 0.48$ & $5.19 \pm 0.37$ & 0.13 \\
$\mathrm{BMI}\left[\mathrm{kg} / \mathrm{m}^{2}\right]$ & $25.83 \pm 4.3$ & $25.16 \pm 4.85$ & 0.49 \\
\hline
\end{tabular}

FBG - fasting blood glucose; BMI — body mass index

Moreover in the total population of our study, the mean value of BMI was $26.68 \pm 4.85 \mathrm{~kg} / \mathrm{m}^{2}$ in Helicobacter infected subjects and $26.25 \pm 5.25 \mathrm{~kg} / \mathrm{m}^{2}$ in non-infected individuals, and there was no statistically significant difference between these two groups $(p=0.57)$.

\section{Discussion}

Type 2 diabetes mellitus is a common systemic disease with serious complications $[1,2,16]$. In recent years, several studies have examined the association between T2DM and $H$. pylori infection and some of them have confirmed this association but others have not shown any relationship between these two. In the present study, the percentage of T2DM patients with $H$. pylori infection was $69.7 \%$ and in the control group it was $66.7 \%$ and the difference between these two groups was not statistically significant. Similar to our study in a cross-sectional study conducted by Jafarzadeh et al. on 100 T2DM patients and 100 healthy controls in 2011 in Rafsanjan city of Iran, there was no significant difference between the prevalence of positive Helicobacter antibodies (IgG) levels among patients with type 2 diabetes and healthy subjects (76\% vs. $75 \%$ respectively). But in their study healthy individuals compared with diabetic patients, had significantly higher levels of anti-Helicobacter IgG antibodies (131.63 \pm 11.68 vs. $54.43 \pm 4.50 \mathrm{U} / \mathrm{ml}$; $\mathrm{p}<0.0001$ ) [17]. Our results are consistent with study by Jafarzadeh et al. regarding the similar rate of $H$. pylori seropositivity in the two study groups and lack of association between T2DM and $H$. pylori infection [17]. However, in our study, the mean serum level of anti-Helicobacter IgG antibiodies in diabetic patients was higher than in the control group $(45.78 \pm 4.82$ and $44.35 \pm 4.83$ respectively), but this difference was not statistically significant ( $p=0.83$ ).

In a study by Bener and colleagues on 210 patients with type 2 diabetes and the same number of non-diabetic patients, a higher percentage of diabetic patients than non-diabetic ones had positive $H$. pylori antibody (lgG) levels $(76.7 \%$ vs. $64.8 \%$ respectively, $p=0.01$ ) which is against our study results [18].

In the research conducted by Devrajani et al. on 74 diabetes cases and 74 non-diabetic controls in Pakistan, the percentage of positive Helicobacter pylori stool antigen was $73 \%$ and $51.4 \%$, respectively and the difference between these two groups in this regard was statistically significant ( $p=0.0001$ ). They suggested that patients with diabetes are susceptible to $H$. pylori infection, therefore they recommended screening for $H$. pylori infection in diabetic patients [19].

Furthermore Bajaj et al. in the study on 80 diabetic patients and 80 controls, showed that the prevalence of $H$. pylori infection in diabetic patients is considerably higher than in the control group $(77.5 \%$ vs. $58.3 \%$ respectively, $p=0.02$ ). Also, in their study the average $\mathrm{HbA}_{1 \mathrm{c}}$ levels in the diabetic group with $H$. pylori was significantly higher than those without Helicobacter infection [20].

Therefore, they suggested that $H$. pylori infection is associated with higher $\mathrm{HbA}_{1 \mathrm{c}}$ levels and inappropriate blood glucose control, but our study results are not consistent with the results of the study by Bajaj et al.

In a study by Zojaji et al. on 85 T2DM patients in Iran, the mean serum $\mathrm{HbA}_{1 \mathrm{c}}$ level 3 months after treatment of $H$. pylori infection was significantly reduced compared to its pre-treatment level, however, fasting blood glucose did not change significantly after treatment compared to the pretreatment state. They 
concluded that $H$. pylori eradication has beneficial effects on the glycemic control in diabetic patients [21]. However, Wada and colleagues, in a retrospective study in Japan, showed that treatment of Helicobacter pylori infection in T2DM patients does not improve $\mathrm{HbA}_{1 \mathrm{c}}$ levels [22].

Also Vafaeimanesh et al. in the study on T2DM patients who were treated with oral medications showed that $H$. pylori infection therapy has no beneficial effects on blood glucose profiles, in addition they had lower rates of successful response to anti $H$. pylori regimen compared with non-diabetic subjects [23].

The study of Quatrini et al. in Italy, also supports the higher percentage of $H$. pylori infection in diabetic patients population (insulin dependent and non-insulin dependent) compared with non-diabetic subjects (69\% and $46 \%$ respectively, $p=0.007$ ) [24]. Although the different outcomes of their study comparing to our study may be due to the fact that they used respiratory urease test for the detection of $H$. pylori infection, while we have used ELISA method (anti $H$. pylori lgG levels).

Our study shows that there is no significant relationship between $H$. pylori infection and type 2 diabetes.

$H$. pylori infection diagnostic tests are classified into two categories of invasive and non-invasive tools and various previous studies have used either one method alone or a combination of several methods $[25,26]$

Although urea breath test is more accurate and commonly used as a standard diagnostic test $[25,26]$, we did not use it because of its high cost and unavailability in our center.

Among the different methods for $\mathrm{H}$. pylori infection detection, we used serology (ELISA) becauseof its convenience and availability and its low cost in this study. Although serologic results also usually not influenced by antibiotic or PPI (proton pump inhibitors) treatment [26], we did not include subjects that were taking PPI or anti-helicobacter medications within one month before the study.

One of the limitations of our study is the use of only one method (ELISA) for the diagnosis of $H$. pylori infection. As mentioned earlier given the high cost of respiratory urease test and its unavailability as well as the financial limitations we could not use neither this test nor any additional method such as $H$. pylori fecal antigen test to confirm the diagnosis of $H$. pylori infection.

Another limitation of our study was the lack of assessment of the upper gastrointestinal symptoms in diabetic patients and not considering it as the inclusion criteria, although most of participants were asymptomatic and did not report any significant upper gastrointestinal symptoms.

Factors such as race, geographic region, economic state, different dietary and drug regimens used to control blood glucose, as well as different diagnostic methods used to detect $H$. pylori infection, can influence the results of different studies.

More prospective studies with long-term followup of $H$. pylori infected patients in terms of the risk of type 2 diabetes development are needed. These studies should use more accurate methods or a combination of several diagnostic tools for $H$. pylori infection what can be helpful in revealing the relationship between $H$. pylori infection and diabetes. As well as future research on the role of oral hypoglycemic drugs may be useful in the development of $\mathrm{H}$. pylori infection in diabetic type 2 patients.

\section{Conclusion}

Based on the results of this study, it seems that there is no relationship between $H$. pylori infection and type 2 diabetes.

\section{Acknowledgements}

The authors of the study thank for the material support of vice Chancellor for research and technology of Urmia University of Medical Sciences and also the work of Ms. Parvin Ayremlou MSC of epidemiology from Clinical Research Development Unit of Imam Khomeini Hospital, Urmia University of Medical Sciences, Urmia, Iran for statistical analysis of our data.

\section{Conflict of interest}

The authors declare to have no conflict of interest.

\section{REFERENCES}

1. Esteghamati A, Larijani B, Aghajani MH, et al. Diabetes in iran: prospective analysis from first nationwide diabetes report of National Program for Prevention and Control of Diabetes (NPPCD-2016). Sci Rep. 2017; 7(1): 13461, doi: 10.1038/s41598-017-13379-z, indexed in Pubmed: 29044139.

2. Noshad S, Afarideh M, Heidari B, et al. Diabetes care in Iran: where we stand and where we are headed. Ann Glob Health. 2015; 81(6): 839-850, doi: 10.1016/j.aogh.2015.10.003, indexed in Pubmed: 27108151.

3. Azimi-Nezhad M, Ghayour-Mobarhan M, Parizadeh MR, et al. Prevalence of type 2 diabetes mellitus in Iran and its relationship with gender, urbanisation, education, marital status and occupation. Singapore Med J. 2008; 49(7): 571-576, indexed in Pubmed: 18695867.

4. Logan RP, Walker MM. ABC of the upper gastrointestinal tract: Epidemiology and diagnosis of Helicobacter pylori infection. BMJ. 2001; 323(7318): 920-922, doi: 10.1136/bmj.323.7318.920, indexed in Pubmed: 11668141

5. He C, Yang Z, Lu NH. Helicobacter pylori infection and diabetes: is it a myth or fact? World J Gastroenterol. 2014; 20(16): 4607-4617, doi: 10.3748/wjg.v20.i16.4607, indexed in Pubmed: 24782613. 
6. Eskandarian R, Ghorbani R, Shiyasi M, et al. Prognostic role of Helicobacter pylori infection in acute coronary syndrome: a prospective cohort study. Cardiovasc J Afr. 2012; 23(3): 131-135, doi: 10.5830/CVJA-2011-016, indexed in Pubmed: 22555636.

7. Shi WJ, Liu W, Zhou XY, et al. Associations of Helicobacter pylori infection and cytotoxin-associated gene $A$ status with autoimmune thyroid diseases: a meta-analysis. Thyroid. 2013; 23(10): 1294-1300, doi: 10.1089/thy.2012.0630, indexed in Pubmed: 23544831.

8. Asadi-Pooya AA, Dehghani SM, Petramfar P, et al. Helicobacter pylori infection in patients with epilepsy. Seizure. 2012; 21(1): 21-23, doi: 10.1016/j.seizure.2011.08.011, indexed in Pubmed: 21903421.

9. Nielsen HH, Qiu J, Friis S, et al. Treatment for Helicobacter pylori infection and risk of Parkinson's disease in Denmark. Eur J Neurol. 2012; 19(6): 864-869, doi: 10.1111/j.1468-1331.2011.03643.x, indexed in Pubmed: 22248366.

10. Roubaud-Baudron C, Krolak-Salmon P, Quadrio I, et al. Impact of chronic Helicobacter pylori infection on Alzheimer's disease: preliminary results. Neurobiol Aging. 2012; 33(5): 1009.e11-1009. e19, doi: 10.1016/j.neurobiolaging.2011.10.021, indexed in Pubmed: 22133280.

11. Kayar Y, Pamukçu Ö, Eroğlu H, et al. Relationship between Helicobacter pylori infections in diabetic patients and inflammations, metabolic syndrome, and complications. Int J Chronic Dis. 2015; 2015: 290128, doi: 10.1155/2015/290128, indexed in Pubmed: 26464868.

12. Serghei C, Emilia T, Natalia F. Helicobacter pylori and type 2 diabetes mellitus: searching for the links. Russian Open Medical Journal. 2016; 5(2).

13. Chung GE, Heo NJu, Park MJ, et al. Helicobacter pylori seropositivity in diabetic patients is associated with microalbuminuria. World J Gastroenterol. 2013; 19(1): 97-102, doi: 10.3748/wjg v19.i1.97, indexed in Pubmed: 23326169.

14. Demir M, Gokturk HS, Ozturk NA, et al. Helicobacter pylori prevalence in diabetes mellitus patients with dyspeptic symptoms and its relationship to glycemic control and late complications. Dig Dis Sci. 2008; 53(10): 2646-2649, doi: 10.1007/s10620-007-0185-7, indexed in Pubmed: 18320319.

15. Anastasios R, Goritsas C, Papamihail C, et al. Helicobacter pylori infection in diabetic patients: prevalence and endoscopic findings. Eur J Intern Med. 2002; 13(6): 376, doi: 10.1016/s09536205(02)00094-8, indexed in Pubmed: 12225782

16. Chen L, Magliano DJ, Zimmet PZ. The worldwide epidemiology of type 2 diabetes mellitus--present and future perspectives. Nat Rev
Endocrinol. 2011; 8(4): 228-236, doi: 10.1038/nrendo.2011.183, indexed in Pubmed: 22064493.

17. Jafarzadeh A, Rezayati MT, Nemati M. Helicobacter pylori seropositivity in patients with type 2 diabetes mellitus in south-east of Iran. Acta Med Iran. 2013; 51(12): 892-896, indexed in Pubmed: 24442545.

18. Bener A, Micallef R, Afifi M, et al. Association between type 2 diabetes mellitus and Helicobacter pylori infection. Turk J Gastroenterol. 2007; 18(4): 225-229, indexed in Pubmed: 18080918.

19. Devrajani BR, Shah SZ, Soomro AA, et al. Type 2 diabetes mellitus: A risk factor for Helicobacter pylori infection: A hospital based case-control study. Int J Diabetes Dev Ctries. 2010; 30(1): 22-26, doi: 10.4103/0973-3930.60008, indexed in Pubmed: 20431802

20. Bajaj S, Rekwal L, Misra SP, et al. Association of helicobacter pylori infection with type 2 diabetes. Indian J Endocrinol Metab. 2014; 18(5): 694-699, doi: 10.4103/2230-8210.139235, indexed in Pubmed: 25285288.

21. Zojaji H, Ataei E, Sherafat SJ, et al. The effect of the treatment of Helicobacter pylori infection on the glycemic control in type 2 diabetes mellitus. Gastroenterol Hepatol Bed Bench. 2013; 6(1): 36-40, indexed in Pubmed: 24834243.

22. Wada $Y$, Hamamoto $Y$, Kawasaki $Y$, et al. The Eradication of Helicobacter pylori does not Affect Glycemic Control in Japanese Subjects with Type 2 Diabetes. Jpn Clin Med. 2013; 4: 41-43, doi: 10.4137/JCM.S10828, indexed in Pubmed: 23966817.

23. Vafaeimanesh J, Rajabzadeh $R$, Ahmadi A, et al. Effect of Helicobacter pylori eradication on glycaemia control in patients with type 2 diabetes mellitus and comparison of two therapeutic regimens. Arab J Gastroenterol. 2013; 14(2): 55-58, doi: 10.1016/j. ajg.2013.03.002, indexed in Pubmed: 23820501.

24. Quatrini M, Boarino V, Ghidoni A, et al. Helicobacter pylori prevalence in patients with diabetes and its relationship to dyspeptic symptoms. J Clin Gastroenterol. 2001; 32(3): 215-217, doi: 10.1097/00004836-200103000-00006, indexed in Pubmed: 11246346.

25. Patel SK, Pratap CB, Jain AK, et al. Diagnosis of Helicobacter pylori: what should be the gold standard? World J Gastroenterol. 2014; 20(36): 12847-12859, doi: 10.3748/wjg.v20.i36.12847, indexed in Pubmed: 25278682.

26. Wang YK, Kuo FC, Liu CJ, et al. Diagnosis of Helicobacter pylori infection: Current options and developments. World J Gastroenterol. 2015; 21(40): 11221-11235, doi: 10.3748/wjg.v21. i40.11221, indexed in Pubmed: 26523098. 